\title{
Fernando Vallejo biógrafo. La vida de los otros y la potencia de la autofiguración*
}

\author{
Julia Musitano*
}

\begin{abstract}
Resumen
En este trabajo, me interesa resaltar la obra biográfica de Fernando Vallejo (El mensajero, Almas en pena chapolas negras y El cuervo blanco) para dar cuenta de las modulaciones de lo autobiográfico en la narrativa de un mismo autor. Cuando un escritor decide contar el pasado íntimo de otro escritor se ponen en juego ciertos procesos que ponen en evidencia no sólo el carácter ambiguo inherente al propio género biográfico sino también la tensión entre la idea de una vida como proceso y la biografía como convención. Al mismo tiempo, la figura del autor-narrador se tensiona entre el biógrafo profesional y el escritor movido por el deseo de indagar en otro escritor. Por esto, sería enriquecedor poner en paralelo lo que hace Vallejo consigo mismo en las autoficciones y lo que hace con la vida de los otros en las biografías.
\end{abstract}

Palabras clave: biografía, autoficción, Fernando Vallejo.

\section{Fernando Vallejo as biographer. Other's lives and the power of self-figuration}

\begin{abstract}
This article highlights the biographical work of Fernando Vallejo (El mensajero, Almas en pena chapolas negras and El cuervo blanco) to show his own self-figurative modulations. When a writer decides to tell the intimate past of another writer, he deals with certain processes that show not only typical ambiguities of the biography as a genre, but also the complex relationship between the idea of life as a process, and the one that considers biography as a convention. At the same time, the figure of the author-narrator experiences two roles that, at some extent, oppose each other: the professional biographer versus the desire of researching and knowing about the life of the other writer. In consequence, it would be enriching to contrast what Vallejo does with himself when he writes autofictions, and what he does with the life of others while writing biographies.
\end{abstract}

Keywords: biography, autofiction, Fernando Vallejo.

\footnotetext{
* Este artículo fue presentado en las Jornadas "Vidas ajenas: perfiles, retratos y biografías latinoamericanos", organizadas por el Insituto de Estética de la Pontificia Universidad Católica de Chile y el CIDOC de la Facultad de Comunicaciones y Humanidades de la Universidad Finis Terrae, que se llevaron a cabo los días 24 y 25 de mayo de 2016 en Santiago de Chile.

** Argentina, Doctora en Literatura. Universidad Nacional de Rosario/CONICET. Rosario, Argentina. musitanoj@gmail.com
} 
Somete su pluma a su caligrafía

Hasta que sea tan natural Firmar con su nombre como con el tuyo

Renguea igual que él,

Presta sus mismos juramentos Si él se vestía de negro, adóptalo también

Si tenía dedos gotosos

Que los tuyos lo sean.

(Robert Graves, ctdo. por Michael Holroyd en Cómo se escribe una vida)

A Vallejo la investigación sobre la vida de Barba Jacobㄹ le tomó diez años, recopiló un libro de poemas y un epistolario, y escribió dos biografías distintas sobre él. La primera aparecida en 1984, en Séptimo Círculo de México, está escrita en tercera persona, se titula Barba Jacob el mensajero y empieza así: "El doce de abril de 1927, tras un ir y venir incierto de veinte años por tierras de Centro América y de México y por islas del Caribe, regresó Barba Jacob a Colombia por el puerto de Buenaventura" ${ }^{2}$ (11). Sobre el mismo material escribió la segunda biografía, totalmente distinta, que fue publicada en 1991 por Planeta Colombiana, con el título El mensajero, ahora escrita en primera persona y que empieza así: “Camino de la muerte, en México, conocí a Edmundo Báez que me habló de Barba Jacob"3 (7). De ambas biografías se hicieron varias ediciones, pero Vallejo decidió que quedara sólo la segunda, y con el título de la primera, Barba Jacob el mensajero. La primera versión, la de 1984, está escrita toda en tercera persona salvo por las últimas páginas en las que cuenta el proceso de investigación y la conmemoración del centenario del poeta. Semejante decisión es una rareza para el mayor defensor de la primera persona en la literatura de América Latina ${ }^{4}$. Además, cuenta Daniel Balderston, que la primera edición de la segunda versión, es decir, de la versión en primera persona, se anunciaba como el quinto tomo de El río del tiempo, pero que después se desprende. El río del tiempo es un ciclo autobiográfico compuesto por cinco autoficciones que cuentan la

1 Porfirio Barba Jacob (1883-1942, Colombia) es uno de los pseudónimos del escritor colombiano Miguel Ángel Osorio. Fue un poeta modernista reconocido en Colombia y en América Latina por sus poemas y su trabajo como periodista.

2 De esta versión utilizaré la siguiente edición: Barba Jacob el mensajero. Bogotá, Planeta Colombiana Editorial, 1997.

3 De esta versión utilizaré la siguiente edición: Barba Jacob el mensajero. Bogotá, Alfaguara, 2008.

4 Fernando Vallejo es reconocido por su rotunda diatriba contra el narrador omnisciente de la novela decimonónica. Toda su literatura está escrita en primera persona, a partir de la propia vida. En Peroratas (2013), libro que recopila ensayos, ponencias en congresos y declaraciones públicas, pueden leerse cantidad de argumentos en contra de la novela en tercera persona. 
vida de Vallejo en clave ficticia. Su publicación sale por tomos desde la primera, Los días azules del año 1985, hasta la última, Entre fantasmas, de 1993. Se filtró, a su vez, más de cien veces el Barba Jacob periodista en el primer trabajo de Vallejo, Logoi una gramática del lenguaje literario, de 1983, piedra angular de su literatura. Estos datos parecen, hasta aquí, un mero anecdotario. Sin embargo, son ellos los que nos van a ayudar a descomponer el monumento que Vallejo le ha hecho a la primera persona en toda su literatura y cómo la escritura sobre las vidas ajenas lo inicia en un proceso paralelo de autofiguración y desintegración que no ha cesado nunca.

Vallejo descubre, y esto es de suma importancia porque es el segundo libro que publica un Vallejo joven, al final de la primera versión de $E l$ mensajero, que hablar desde la primera persona es un modo de construir el relato. La primera edición de la biografía comienza en tercera persona, pero en el final aquella se convierte en el yo que Vallejo ya no abandonará ("Iré a Santa Rosa de Osos a buscarte, a buscarme" (1997, 518)). Una decisión ética y estética -hablar en primera persona de uno mismo- que casualmente surge en la escritura sobre otro. Una biografía de la que se desprende la escritura de lo propio, y simultáneamente, una autobiografía que se desmenuza en la escritura de lo ajeno.

Sabemos que la biografía es un género tan viejo como el mundo, que ha sobrepasado las debacles de la historia humana, y que la historiografía se ha dedicado a estudiarla con exhaustividad. Pero también sabemos que la influencia de la literatura en un género muy cercano a la Historia (con mayúscula) trastoca las leyes a las que éste se somete. Se suponía que el biografiado es digno de ser narrado porque se constituye en paradigma, en un modelo ejemplar hasta que lo vemos transformarse en el protagonista del drama de su propia vida. Las biografías literarias trazan perfiles de excéntricos, de personalidades éticamente dudosas, de hombres que no tienen mucho para mostrar más que sus rarezas. Digo rarezas pensando específicamente en la publicación, en 1896, de Los raros de Rubén Darío, que marca un quiebre en los modos de constitución de un género literario: la biografía en América Latina. Darío construye allí siluetas de escritores (atípicos, singulares, únicos por motivos diversos) para construir su propia imagen de escritor en un momento particular de la cultura latinoamericana. Me interesa pensar que en Los raros hay un gesto fundador de un género literario que hoy, en el siglo XXI, varios autores latinoamericanos ponen en práctica. Construir un relato de vida 
a propósito de un escritor provocador, insolente, raro, decadente, dandy del siglo XIX, para construirse a sí mismos en la entrada a este nuevo siglo. Retratar una figura para figurarse, biografiar para autobiografiarse. Incluso, podría aventurar a decir que las biografías de Vallejo escritas a finales de los '80 (al menos las dos primeras) son las que abren esta tradición de escritores que escriben sobre otros escritores y lo hacen en el marco de la propia literatura jugando con los parecidos y las desemejanzas ${ }^{5}$.

Marcel Schowb (1998), referencia obligatoria de la teoría sobre la biografía, confirma que las singularidades, las anomalías y las manías de los grandes hombres son las que interesa librar a lo azaroso y a lo fragmentario de la literatura. Los pequeños detalles, las migajas, los restos, las cenizas que deja el muerto son los rasgos que definen a un hombre mucho más allá de sus logros que son patrimonio común de la humanidad (398-406). Una biografía literaria no tiene la necesidad de retratar las grandes hazañas de un sujeto, sino más bien hacer foco en los hechos menores, dice Patricio Fontana, en los que el biógrafo captará aquello por lo cual quiere relatar una vida (Vidas americanas ${ }^{6}$ ). La narrativa biográfica, y más aún la que diseña perfiles literarios, se nutre de los residuos de la vida: algunas cartas perdidas, varias facturas de hotel impagas, un diario de contabilidad. Y aquí es fundamental detenerse en que Vallejo es un escritor que escribe sobre otros escritores, no es un biógrafo ensayista o un biógrafo académico que se dedicó a escribir sobre la vida de dos poetas y un gramático colombianos. Es un escritor particular, cuya obra narrativa está escrita en primera persona y en nombre propio, es un escritor que se ha dejado arrastrar por sus recuerdos en cada una de sus intervenciones literarias. Ese que no puede callarse lo propio es el que escribe sobre Porfirio Barba Jacob primero, sobre José Asunción Silva después, y sobre Rufino José Cuervo más tarde.

Si acordamos en que la biografía literaria es un incómodo género que oscila entre los divertimentos literarios y el rigor de las ciencias sociales, podemos agregar que en las biografías de escritores -más aún si están escritas por otro escritor que no hace otra cosa que contar su pro-

5 Estoy pensando en biografías como las de Carlos María Domínguez (sobre Roberto de las Carreras y Juan Carlos Onetti), Ricardo Strafacce (sobre Osvaldo Lamborghini), Osvaldo Baigorria (sobre Néstor Sánchez), Mariana Enríquez (sobre Silvina Ocampo), Jorge Edwards (sobre Joaquín Edwards Bello y Pablo Neruda).

6 El libro de Patricio Fontana Vidas americanas. Usos de la biografía en Domingo Faustino Sarmiento, Juan Bautista Alberdi y Juan María Gutiérrez está en prensa en la editorial Eudeba con miras a publicarse este año. 
pio pasado- se superponen la idea de una vida como proceso y la forma de la biografía como convención. Sabemos que la biografía, aunque se fundamente en su falta de definición exacta, cuenta con unos límites y condiciones bien definidos y no inmanentes: los datos de la realidad, los hechos. El punto clave para definir la biografía literaria está en pensar en la forma que el biógrafo decide darle a esos datos, cómo va a mostrar "el movimiento de una vida y la trayectoria de un pensamiento" (54), dice Benoit Peteers (2010), quien escribió un diario sobre la escritura de la biografía de Derrida (Trois ans avec Derrida). Patricio Fontana plantea, en el mismo sentido, que el vínculo entre biografía y literatura se da por dos cuestiones fundamentales: el carácter del texto biográfico como artificio literario y la consolidación del concepto de autor (Vidas americanas). La biografía de escritor no se define ni por una interpretación analíticocrítica de sus textos, ni por un modo de retratar la época en la que ese escritor vivió, ni siquiera por su propia persona, dice Aldo Mazzucchelli (2016) a través de su definición de ensayo biográfico, sino por la potencia imaginaria que une la obra y la vida del biografiado. Las biografías literarias nos dan la posibilidad de hacer literatura con el mundo y la vida de un escritor (Mazzucchelli). Por eso, es importante observar allí el sentido de la aparición de lo autobiográfico: de la intromisión, a veces discreta a veces impune, del biógrafo en la vida del sujeto biografiado en proceso de construcción, y simultáneamente la intrusión de la vida y la literatura del biografiado en los relatos del biógrafo. En el misterio a descubrir del otro, nos enseña Judith Podlubne (2016), nos encontramos con lo desconocido de uno mismo.

La ambigüedad del juego que propone la literatura de Vallejo entre vida y escritura, entre narración e invención es tal que, siguiendo a Giordano (2011), podría decirse que Vallejo experimenta en la escritura de sí mismo la íntima ajenidad, y simultáneamente, experimenta en la escritura de los otros, la ajenidad más propia.

Voy a terminar este recuento de mis contados amores a quienes no conocí, con un poeta más, de Antioquia justamente, y que partió justamente en el instante mismo en que vine yo. Ya en un verso lo había dicho: <De mano en mano, la antorcha va encendida $>$. En los múltiples giros de la vida, en un país extranjero, prisionero en la celada de sus versos empecé a vislumbrar que otro antes que yo había vivido mis momentos y recorrido mis caminos, y desandando mis pasos lo empecé a buscar, me 
empecé a buscar, tras de su huella, volviendo sobre la mía: por Cuba, por Costa Rica, por Honduras, por Nicaragua, por El Salvador, por México, por el Perú. <Yo no sabía que el azul mañana es vago espectro del brumoso ayer...> Siete años lo busqué, para encontrarme yo. (Vallejo Los días azules 193-194)

La relación del biógrafo con su sujeto es el corazón de la empresa biográfica. Todos los teóricos sobre biografía han hecho hincapié en esto, ya sea para dar consejos de escritura sobre cómo no dejarse apoderar por el biografiado, ya sea para explicar la relación con el otro. En definitiva, la escritura biográfica se acerca de modo irrefutable a ese movimiento hacia el otro y a la alteración del yo, hacia la construcción de un sí mismo que se ha convertido en otro. El problema de la identificación se encuentra en el centro de la biografía moderna, dice Edel (1990). ¿Cuál es la relación que construye Vallejo con Silva y Barba Jacob? ¿Cómo seguirle la huella a un muerto e identificarse con él? Peteers (2010) señala que no hay biografía sino es la de un muerto. Se trataría de una colaboración in absentia. El biografiado forma parte de la vida del biógrafo como una suerte de amigo póstumo. Las historias que cuenta Vallejo de cada uno de sus biografiados resuenan evidentemente en la escritura de las autoficciones como ecos, huellas, restos. El biógrafo se esfuma, se desintegra, se pierde en la escritura ajena para adentrarse en la propia con la carga de la supervivencia. César Mckensie (2013) aclara: "Y sólo así la biografía se vuelve autobiografía, especulación sí, inquietud, dolor, melancolía. Es el testimonio de una voz degradada que cuenta la vida de otro como si fuera la propia" (352).

Para dar cuenta de la puesta en común de las reglas de un género eminentemente histórico y los avatares de la creatividad literaria, y para respetar la sistematización a la que el biógrafo Fernando Vallejo dice someterse en la escritura de sus biografías, parecería posible definir un método y un orden con los que trabaja la narración de vidas ajenas. En cuanto al método, Vallejo especuló con la vida de sus biografiados a partir de la trayectoria de una creación poética y del movimiento afectivo que une la leyenda del personaje y las premuras de su vida. $Y$ decir eso no es decir poco: Barba Jacob es, primero, un poeta desterrado, como dice Foffani (1997), porque tenía un pie en el modernismo y otro en la vanguardia; segundo, un poeta cuya obra fue fagocitada por la leyenda que creó en vida; y tercero, es un dandy extraditado y enfermo que vivió exiliado en una veintena de países con una infinidad de seudónimos, de hotel en hotel, de hospital en hospital. Por ende, una biografía sobre 
semejante especimen de las letras colombianas, escrita por un personaje tan controversial como Vallejo, que quiere construir una leyenda sobre sí, no puede ser sino, al menos, elíptica, errática, un sistema extraordinario de suposiciones y conjeturas. En cuanto al orden, no hay orden posible para el recuerdo. Es decir, cada una de las biografías de Vallejo nos presenta mucho más que una vida desordenada, porque el eje está puesto en el discurrir de los recuerdos propios y ajenos, en la selección de aquellos momentos de la vida del otro que le permiten a Vallejo presumir sobre los propios. El orden que él le da a la vida de sus biografiados es el mismo que el que le da en sus autoficciones: recordar en la espera de una muerte segura.

Ambas versiones de El mensajero se empeñan en presentar la vida de Barba Jacob desarticulada, nada cronológica, rompiendo, al menos, el canon sincrónico del género biográfico. En la primera, el yo no se manifiesta con la fuerza de las narraciones posteriores y se define como un maremágnum de citas y comillas que dan cuenta de la obra y la vida de uno de los poetas más raros y excéntricos que ha dado la literatura latinoamericana. En la segunda, el yo es llevado al extremo y Vallejo se constituye en un biógrafo cuyo único objetivo es ganarle la pulseada a la muerte.

En adelante, todas mis partidas con la muerte, se las gané. Pero no voy a envanecerme ni a ponerme a presumir; la verdad es que seguí sintiendo siempre, en cada nuevo encuentro con cada nuevo conocido que en mayor o menor grado, por un motivo u otro, hubiera tenido que ver con Barba Jacob, la misma vieja incómoda sensación de lo imposible, de que vivieran los muertos. (El mensajero 2008 315)

La narrativa de Vallejo atesora, en un cúmulo de proliferaciones, a pura pérdida, acumula cuantas ausencias puede, y en ese mismo movimiento se rehúsa a la reconciliación. La apuesta es sostenerse inestable entre la irrealidad de un tiempo perdido, y el encuentro imposible con lo muerto. Vallejo asegura que todas las partidas que tuvo con la muerte se las ganó, que, en las biografías particularmente, pudo darle vida, al menos, a tres muertos; y en las autoficciones, a otros tantos. Sin embargo, no es la muerte la que se llena de vida en los relatos sobre Barba Jacob, Silva y Cuervo, sino, muy por el contrario, es la vida la que se llena de muerte. Y lejos de revivir a los muertos, lo que logra es ir él muriéndose de a poco. En mis palabras: cuánto más quiero que vuelvan, que vivan 
junto a mí lo que han vivido, más se mueren ellos, más me muero yo. Demuestra, a través de la potencia disruptiva del recuerdo, que en el gesto de volver a vivir presiona con insistencia el volver a morir, el hacer acto de la ausencia.

Colombiano devenido mexicano, periodista mercenario, defensor de ideas liberales, homosexual, sifilítico, marihuanero, alcohólico, maldito engominado de espíritu conservador, poeta y oportunista, contradictorio hasta la médula; todo eso era Porfirio Barba Jacob. Y su paradoja más grande, empero, reside en la variedad de nombres con los que vivió. Nació como Miguel Ángel Osorio, se fue de Colombia como Ricardo Arenales, volvió una veintena de años más tarde como Porfirio Barba Jacob y en sus textos, de vez en cuando, se nombraba Maín Jiménez. Poeta de los múltiples nombres, y sobre todo un gran simulador. Hizo una leyenda de sí mismo, construyó un personaje por fuera de los libros y le dejó un gran legado a Vallejo: la capacidad de posar (de hacerse pasar por otro) hasta la muerte. Porfirio Barba Jacob le enseñó a Vallejo que vivir es esforzarse, cuenta Juan Gabriel Vásquez (2011), y el esfuerzo consiste en "lavarse la máscara antes que la cara, en crearse un personaje" (156).

Una escena, que aparece en ambas versiones de la biografía, la escena inmediatamente anterior a la muerte del poeta, relatada por Vallejo a partir de algunas necrológicas y del testimonio de Rafael Delgado (el amante-hijo adoptivo de Barba Jacob), sólo los pocos párrafos que dura esa escena, sólo la destreza técnica con la que Vallejo narra esa escena es capaz de iluminar el resto de su literatura. Hacia el final de su vida, Barba Jacob decide en plena extremaunción, volver a llamarse Miguel Ángel Osorio. Decide morirse con el mismo nombre con el que fue bautizado y hacer huecos los viejos nombres, vaciarlos de sentido:

Y cuando el sacerdote iba a impartirle la bendición papal y le preguntó cómo quería que lo nombrara en las oraciones, conmovido le respondió: “Miguel Ángel”, el nombre con que lo habían bautizado en la iglesia Santa Rosa de Osos. ¿Pero de verás era Miguel Ángel Osorio? Yo siempre pensé que era Barba Jacob, ex Maín Jiménez, ex Ricardo Arenales, el heresiarca, el apóstata, el que rompiendo la ilusoria continuidad del yo iba camino a llamarse, suprema burla, Juan Pedro Pablo, para diluir su persona estorbosa en el nombre del nadie, en la total desintegración. (El mensajero 2008 435) 
Claro que Vallejo creyó eso, y cualquier lector de la biografía creería eso y se sorprendería con la última decisión de Barba Jacob. Porque la relación entre la persona real y la pose que encarna, ya sea para las exigencias de una obra de arte o para manejarse ante la vida son, en el caso de estos personajes extravagantes, difíciles de dilucidar. Es decir, realidad y ficción, rostro y máscara, nombre y seudónimo, vida y obra se conjugan de tal modo que no pueden separarse, que la vida deviene literaria, el seudónimo nombre, y detrás de la máscara ya no se encuentra nada.

Este mismo episodio, que difiere en la primera edición de la biografía, abona a la confusión:

Ya al final, empero, mientras se disponía a cruzar el umbral de la última puerta, creyó haber vivido equivocado, que era verdad la falacia y que por sobre la diversidad aparente él había sido siempre uno mismo: Miguel Ángel Osorio, como le habían bautizado en la iglesia de Santa Rosa de Osos. Era entonces cuando se equivocaba: Miguel Ángel Osorio no era más que un fantasma entre muchos de un remoto y ajeno pasado. (Almas en pena 510)

Lo único que les permite el pasaje entre la máscara y lo informe a Barba Jacob, y a Vallejo en las autoficciones, es la muerte. Cuando digo pasaje no digo cambio, ruptura, digo paso, estancia, estar en el mismo instante en dos posiciones distintas. Ese instante constituye para Vallejo una decisión estética y ética para la continuidad de su propia literatura. En el último remanso que le queda de vida, Barba Jacob decide dejar de posar, que es lo mismo que dejarse morir. Vallejo decide en el resto de su literatura que en la imposibilidad de morirse, seguirá posando a pesar que en el acto de ser y no ser él mismo, se desintegre, se esfume, se diluya tras la mascarada.

\section{Bibliografía}

Darío, Rubén. Los raros. Buenos Aires, La Vasconia, 1896.

Dosse, François. El arte de la biografia. México, Universidad Iberoamericana, 2007.

Edel, León. Vidas ajenas. Principia biographica. Evangelina Nuño de la Selva Trad. Buenos Aires, Fondo de Cultura Económica, 1990. 
Foffani, Enrique. "Las máscaras del poeta: sobre la poesía de Porfirio Barba Jacob". Orbis Tertius, año 2, no. 5, 1997, p 117-127.

Fontana, Patricio. Vidas americanas. Usos de la biografía en Domingo Faustino Sarmiento, Juan Bautista Alberdi y Juan María Gutiérrez. Buenos Aires, Eudeba, en prensa.

Giordano, Alberto. La contraseña de los solitarios. Rosario, Beatriz Viterbo, 2011.

Holroyd, Michael. Cómo se escribe una vida. Ensayos sobre biografía, autobiografía y otras aficiones literarias. Buenos Aires, La Bestia Equilátera, 2011.

Mckensie, César. "Ceremonias del exhumador: lectura descriptiva de El mensajero y Chapolas negras". Fernando Vallejo. Hablar en nombre propio. Luz Mary Girardo y Néstor Salamanca-León Eds. Bogotá, Universidad Nacional de Colombia, 2013.

Mazzucchelli, Aldo, "La biografía y su forma. Una lectura de Adorno." Actas IV Coloquio Internacional 'Literatura y Vida', CELA, 2016. Disponible en: http://www.celarg.org/int/arch_coloquios/mazzucchelli.pdf

Peteers, Benoit. Trois ans avec Derrida. Paris, Flammarion, 2010.

Podlubne, Judith. "La biografía como forma”. Ponencia presentada en el Argentino de Literatura, Santa Fe, 2016.

Ricoeur, Paul. La memoria, la historia y el olvido. Madrid, Trotta, 2003.

_. Sí mismo como otro. Buenos Aires, Siglo XXI, 2011.

Schwob, Marcel. "El arte de la biografía”. Vidas imaginarias. AA.VV. Buenos Aires, Emecé, 1998.

Vallejo, Fernando. Logoi. Una gramática del lenguaje literario. México D.F., Fondo de Cultura Económica, 1983. Almas en pena, Chapolas negras. Bogotá, Alfaguara, 2008. . Barba Jacob, el mensajero. Bogotá, Alfaguara, 2008.

_.. Barba Jacob, el mensajero. Bogotá, Planeta, 1991.

_.. El cuervo blanco. Buenos Aires, Alfaguara, 2012. . Los días azules. Buenos Aires, Alfaguara, 2004.

Vásquez, Juan Gabriel. "Porfirio Barba Jacob, el reino estéril de las lágrimas". Los malditos. Guerriero Leila Ed. Santiago, Ediciones Universidad Diego Portales, 2011. 